Article

\title{
Proximity Trade and Urban Sustainability: Small Retailers' Expectations Towards Local Online Marketplaces
}

\author{
Juan-Francisco Delgado-de Miguel ${ }^{1}$, Tamar Buil-López Menchero ${ }^{1}(\mathbb{D}$, \\ Miguel-Ángel Esteban-Navarro ${ }^{2}$ and Miguel-Ángel García-Madurga ${ }^{3, *(1)}$ \\ 1 Department of Marketing, Esic Business \& Marketing School, Vía Ibérica, 28, 50012 Zaragoza, Spain; \\ juanfco.delgado@esic.edu (J.-F.D.-d.M.); tamar.buil@esic.edu (T.B.-L.M.) \\ 2 Department of Documentation Sciences and History of Science, University of Zaragoza, Calle de Pedro \\ Cerbuna, 12, 50009 Zaragoza, Spain; mesteban@unizar.es \\ 3 Department of Business Administration, Betancourt Building, Campus Río Ebro, University of Zaragoza, \\ 50018 Zaragoza, Spain \\ * Correspondence: madurga@unizar.es
}

Received: 23 October 2019; Accepted: 14 December 2019; Published: 16 December 2019

\begin{abstract}
The aim of this research is to identify the expectations offered by small retail businesses towards local online selling platforms as an innovative tool to ensure their future and the urban sustainability. Based on the previous findings obtained from an analysis of trends, actors and marketplaces operating in the retail sector, sixty semi-structured in-depth interviews have been carried out to Spanish local retail managers and owners. Opportunities and risks faced by local online marketplaces are presented from the perspective of small retail stores. Different attitudes towards online shopping platforms have been identified depending on their size, presence and experience in the online world, which has allowed us to categorize local retail businesses in six groups. Despite the perceptual and attitudinal differences between them, it is concluded that merchants have assumed that the current and future business model goes through the digitalization of their businesses and the selling on e-commerce platforms. The coexistence of the e-marketplace and the physical stores, conducted by the same retailers, could have a positive effect on the urban sustainability: on the one hand, with the economic strengthening and renovation of the historical centers and, on the other, with the maintenance of the population and traditional social relationships.
\end{abstract}

Keywords: urban sustainability; online marketplaces; local retail expectations; Zaragoza (Spain)

\section{Introduction}

The crisis that began in 2008, with its direct impact on consumption, has severely affected small businesses, a "silent majority" [1] often ignored [2], despite its importance for economy and employment. In fact, for the European Union, small firms contribute more to job creation than larger firms [3]. Particularly, retail business is a powerful source of economic growth due to the retailers' ability to provide a significant amount of jobs [4].

Small stores also play a very important role for the city and its constant regeneration [5]. Retail presence in urban centers is key to prevent a leakage of spending, offsetting the interest of the population to live outside their locality [6]. Small stores slow down the growing trend towards urban desertification and, therefore, the abandonment of buildings and the decrease of public investments in public services, which constitutes an incentive for crime. The loss of commercial activity is one of the most significant indicators of the decline of urban centers. There is no city without commerce, as it strengthens the urban frame and the social structure of the city [7]. The small local stores constitute a 
key space for the life of the neighborhoods, both for what happens in them, as for their articulation with other spaces where the daily life of the neighborhood develops. They are, therefore, fundamental spaces for sociability, and key to supporting and building community and coexistence [8].

The role of the physical store is changing, and the retail transformation is a real fact. The traditional business model is challenged by the pressure of the digital embrace, imposed by online and offline competitors. On the one hand, the emergence of new online stores, with no physical costs or trading hours restrictions, as well as an extensive portfolio which offers products at low prices [9], together with the rapid expansion of online shopping, which has been, in the meantime, a major cause of change to the structure of traditional high streets [10]. On the other hand, the spread of discount stores and the proliferation of large suburban shopping centers.

Complementing sales with the help of the online channel is presented in this context as a potential great attraction, especially when starting to use online sales and marketing channels with low entry barriers such as local shopping platforms, which allow small businesses to keep in touch with existing customers, explore new markets and start in the world of electronic commerce [11]. In addition, this can be achieved without being passively dependent on the traffic generated by electronic intermediaries, but actively creating links with the customers by means of the new digital contact points of their stores [12].

Despite this, the basis of trade is providing consumers with the products they want in the best possible way. It remains unchanged [13] and requires, in many cases, the "face-to-face" interaction between buyer and seller, as it has been going on for centuries [14], incorporating the changes in the habits and expectations of very well-informed customers.

The coexistence of virtual and physical stores is realistically expected both in the present and in the future. Even e-commerce giants like Amazon are investing in the latter, as evidenced by the acquisition of Whole Foods Market in August 2016, and the fact that $90 \%$ of the global retail sales are still made in physical stores [15]. In the meantime, online channel intermediaries such as online marketplaces connect the supply and demand for goods, information or services, and provide important support to tackle the challenges of the electronic commerce [16]. The retail rules are being rewritten at this time of change. The most successful retailers combine the best of digital and traditional business models in their business strategies [17]. Consumers who buy using a variety of channels are more loyal and spend large sums, so those who offer their products through multiple channels are registering an increase in their total sales [18].

The roles of electronic intermediaries range from the simple outsourcing of end-of-line management (e.g., from the e-commerce website) to the outsourcing of complex marketing and sales processes, including pricing, logistics and billing. Thus, digital sales platforms are having a profound impact on all categories, forcing all the actors to rewrite their channel strategies and management approaches, including how they classify, quote, promote and market their products [19]. Over the past 15 years, online trading platforms have become increasingly popular. Alibaba, Amazon and JD.com increased the gross value of merchandise sold at a staggering 34\% annual rate between 2012 and 2017. Amazon became the third most valuable company on the stock market in 2008, advancing Microsoft and being just behind Apple and Alphabet, clearly showing that customers and investors love their daring experiments to redefine the same concept of online retail [20]. However, despite the impressive growth rates of both electronic commerce and e-marketplaces, this is still a minor channel for the distribution of goods in the European Union [21].

Financial limitations and lack of knowledge and infrastructure are the main difficulties for the generalization which uses digital services among small retailers. The lack of certainty about their potential for business improvement, the return on effort and the adoption costs, add difficulties to the incorporation of small businesses into the digital world [22]. The identification of realistic and immediate benefits encourages the first movement and dissipates these doubts [23]. The use of an e-marketplace will not allow the realization of benefits if the environment is not understood together with the benefits that it can generate [24]. 
Therefore, questions exist, such as, if this small retailers' perception realized in the first days of retail e-commerce at the beginning of the 21st century is still present, and if some other relevant changes in its expectations have appeared in the context of an offer to join a local online marketplace. The research exposed in this article seeks to answer these questions. The paper presented is structured as follows: Identification of a relevant research problem from a review of literature focused on the discussion of the impact of new technologies on small retail surviving and sustainability (Section 1); exposition of the theoretical background and formulation of the research questions to be tested in the study (Section 2); explanation of the qualitative methodology followed (Section 3); presentation and discussion of results (Section 4); and, finally, conclusions and implications of the findings (Section 5).

\section{Theoretical Background and Research Questions}

It can be considered socially relevant to study local retail businesses' perception towards a possible coexistence between the physical and virtual store through a local online commerce platform, given its impact on the design of sustainability strategies for the survival of small stores. The coexistence of direct and online commerce allows connecting supply and demand, speeding up the digital transformation and stimulating sales in local retailers and, therefore, the maintenance of employment and the proper conservation of urban centers in the cities. The proximity trade in the cities of the 21st century, based on the simultaneous and synergistic presence of small stores in the electronic and physical world that cooperate together in the same town or region, can be described as innovative and sustainable from a double perspective that contemplates both the business model and urban sustainability.

First, changing from a store-centered approach to a multi-channel mindset requires the small retailers to change their traditional frames of reference and ways of working [25]. Innovation, collaboration, consolidation, integration and automation are required to revitalize trade, which will have a deep impact in the way these businesses do their activities, now and in the future [26]. Consequently, for those businesses that recognize future challenges and meet customers' demands, there are more opportunities than threats on the horizon. For example, local marketplaces can use the Internet to enhance advertising campaigns that link fresh food and a healthy body, commensality and conviviality, terms that allude to life in common and that mean the quality of our coexistence or ability to live and interact with others in a beneficial way. The Internet can also encourage the interaction with local producers and the coordination with consumer cooperatives for baskets of local products. The groups with a high level of formation and charged with political and socio-ecological commitment appreciate to a high degree the health of the body, linked to the practices of a fresh diet, and coexist in convivial, dense and vertebrate neighborhood spaces [27].

Secondly, the concept of sustainability has grown beyond the idea of environmental stewardship to include social as well as economic goals. In sustainable cities, the sum of positive effects of the interaction of the three environments is greater than the sum of all negative effects. Sustainable cities know how to take advantage of the benefits linked to agglomeration economies (including people, resources, activities and equipment) and keep the carrying capacity of urban space below a certain threshold [28]. Whereas the environmental aspects have been well researched, the connection between social sustainability and urban form has seen a limited number of studies [29].

Polese and Stren [30] define social sustainability as development (and/or growth) that is compatible with the harmonious evolution of civil society, fostering an enabling environment to the coexistence of culturally and socially diverse groups and, at the same time, fostering social integration, with improvements in the quality of life for all segments of the population. Traditionally, the concept of urban social sustainability conceives the city as a meeting point for lasting and meaningful social relationships, which meet the social needs of current and future generations, these being the quality of life of its citizens, the access to housing and services, employment and an acceptable level of income [31]. However, the sustainability is also to establish a socioeconomic equilibrium allowing current and future generations of cities' inhabitants to grow, to live well and to prosper [32]. 
The urban sustainability in their main dimensions (social, economic, environmental and quality of life) is now linked with an intense use of digital technology embedded across all city functions (governance, infrastructure, energy, mobility, healthcare, etc.), in what is known as the "smart city." The European Commission already announced in 2012 that the smart cities would become the engines of sustainable development [33]. The term "smart-sustainable city" has entered the academic discourse as an attempt to connect the sustainable and smart city concept; and empirical work in this field is nascent [34].

The accessibility and usability of information and communication technologies enhanced services appears as a prominent issue of the smart cities debate [35]. The commerce is also concerned. The data warehouses and distributed systems are necessary smart urban applications and the e-marketplaces dedicated to local products, cultural artifacts or to the exchange economy of social business have a prominent place among them [36]. These technologies can help to maintain local commerce in adopting new ways to connect providers and consumers.

Consumption has become the social habit par excellence, and urbanity, meaning intensive random encounters between people, is at the core of a sustainable urban economy [37]. The maintenance of commercial life in the historic center of the cities and disseminated by the arteries of the new neighborhoods helps at the economic, social and environmental sustainability of the cities. Michael Porter already showed that cities' regeneration and renewal include a business-driven approach through business investment, particularly in inner city areas [38]. In developed countries, it is a very well-established fact that urban centers are engines of regional growth [39]. Successful local economies are those which have an efficient internal circulation of disposable income [40]. The flow of ideas and knowledge stimulated by the density of urban centers generates pro-growth effects [41]. Specifically, retail-led regeneration initiatives create a net injection of spending retail within the local economy [42]. Local authorities have promoted retail-led regeneration of deprived inner cities to kickstart lagging localities into generating real economic growth, jobs, and creative and exciting urban spaces [43]. Retailers have a significant influence on sustainability issues due to their position in the supply chain between producers and customers [44].

Many researches have been carried out on how online shopping leads to increased commercial traffic, congestions and hence, pollution in areas with dense population. Aspects of e-commerce sustainability include initiatives that use e-commerce to change organizational processes, practices to improve energy efficiency and reduce the environmental impact; and the introduction of products and/or services which are environmentally healthier [45]. However, the increase of home deliveries does not necessarily mean less efficient deliveries [46], due to its high efficiency and effectiveness, e-commerce led to economic growth, increased profitability and increased value added to output, and hence, resulted in sustainable production activities [47]. So, a balance between the growth of e-commerce and the resulting environmental-social negative effects should be maintained to ensure less harm to the society through pollution [48]. This balance requires a framework to evaluate the performance of sustainable urban development in using natural resource limitations and meeting human welfare needs [49]. At the same time, sustainability is becoming increasingly important for the customer. Due to the growing environmental awareness in today's society, companies are adopting this awareness by starting sustainable initiatives in order to measure and reduce their ecological footprint and to meet customers' demand [50].

New platform-based sharing businesses can transform cities and can help solve the actual urban challenges [51]. The making of smart cities involves a great variety of stakeholders, but the researches have been mainly focused on the citizens' needs and expectations as service users [36], more than in the service providers. Therefore, studying and finding new ways to maintain proximity trade from the perceptions, needs and expectations of small retailers about local e-marketplaces is, undoubtedly, a research gap and a challenge with significant and positive effects on the sustainability of cities. 
Collaboration and networks among firms within a closed-loop supply chain lead to a sustainable business model that can provide benefits to three bottom-line concepts: protecting the environment, improving the economic performance, and enhancing the social performance [52]. According to David Harvey [53], small urban commerces are institutions that reflect changes in relationships of production of contemporary societies, especially in the forms of post-Fordist flexible accumulation. The proximity trade has to play an important role if it wants to be a protagonist and not a victim of these relationships. Electronic marketplaces promoted by local retailers living in coexistence with physical stores are in line with Richard Sennett's proposal [54] that the main challenge of cities today is to build a sustainability model that acts bottom-up and not top-down, thanks to the empowerment of citizens and local actors.

The academic literature on the adoption of electronic commerce by small and medium enterprises is very extensive [55-58]. From retail in the digital age, issues such as consumer engagement and interactivity in online retail channels, price promotions, fraud, online recommendations and product returns have been analyzed [59]. There is also research on the incorporation into the retail trade of technological innovations in the supply chain and the functions of payment, information and billing [60]; the supply-demand process of the retail industry and its valuable estimation models [61]; and how to build enough trust to facilitate transactions [62].

Some studies conclude that competitive pressure and customer expectations have a positive influence on the inclination to adopt new technologies and business models, but a significant number of retailers underestimate the expectations of their customers and are reluctant to add digital services to their business portfolio, moving away from a society that has already adapted to the digital era and is increasingly used to digital sales and services' channels [63]. This incorrect assessment of the new reality suggests a need of public impulse, such as the revitalization of local shopping platforms $[64,65]$ and the search for synergies throughout the value chain with suppliers, local partners and even competitors. Along these lines, Ritala et al. [66] introduce, in the field of electronic platforms, the concept of cooperators, that is, companies capable of generating value through cooperation in this ecosystem compared to what happens in others in which they compete. Infrastructures and shared digital services (apps, logistics management) without the hassle of implementation and maintenance with their own resources, show encouraging results [67], facilitating cost savings for online activities. The idea that local sales platforms and the recent and promising evolution of e-marketplaces can help to overcome these barriers to access to the e-commerce has recently been proposed [68].

Main trends in sustainability and retail research have been identified [69], even if sustainability has received more attention in retail management practice compared to research applications [70]. Additionally, "Retail resilience" has been analyzed as the retail response to online sales [71] and, recently, has been employed to explore the ways in which different material forms of shopping in brick-and-mortar retail spaces (main street, suburban mall, and power center or retail park) may persist as online retailing proliferates [37]. However, attention has not been paid to the prospects, in terms of threats and opportunities that small merchants perceived towards an electronic intermediary offer. Only recent findings [72,73] indicate a clear misalignment between the importance that small business owners attach to digital services and the availability of such services, the current status of their implementation, and even the predisposition of those to participate in the digitalization.

Given this academic context, the aim of this study is to investigate the attitude of small retail businesses towards the possibility of selling in a local online marketplace. A local online marketplace is an e-commerce site which groups sellers from a neighborhood, a city or a region, and puts the focus on the contact with proximity customers, preferably. The transactions in the online marketplace are processed by an operator.

The study poses the following two research questions. First, what is the position of small retailers with respect to local online marketplaces? To provide an answer, a research on the e-commerce model above-mentioned has been carried out, paying special attention to items such as acceptance, rejection, fears and opportunities. Second, which basic support and services are demanded and preferred by small retailers, and consequently needed for this digital transformation? This research seeks to know 
what is the perceived value from small retailers' point of view about the advantages and benefits of the various services offered by the local online shopping platforms.

The research allows to validate the following propositions:

Proposition 1. Expectations depend on the business size.

Proposition 2. Expectations depend on previous online presence.

The contrasts between companies based in quantitative indicators such as the number of employees, annual turnover or profit are quite obvious, and they are common in the management studies. However, digital is different. The digital business maturity is not necessarily more related with the business size than the previous online experience because this experience is based on the existence of relevant elements to digital transformation as the presence of a strategy, talent and technical skills in the company [74]. We have decided to use a classic comparison variable with a new one, in line with the digital world, to discover if there are significant differences based on one or another variable. Additionally, the purpose of confronting retailers with diverse online experience and company size is to discover some type of the categories based on these characteristics.

\section{Materials and Methods}

It was decided to do an exploratory research with the help of a qualitative method: sixty semi-structured in-depth interviews have been carried out to local retail managers and owners.

A non-experimental research strategy has been followed, given that the studied phenomena have been analyzed by observation in their natural context, without seeking their replication in an artificial environment controlled by the researcher. In accordance with the nature of the reality to be studied and the established objective, a qualitative investigation was chosen. The use of quantitative techniques was discarded because of the exploratory and non-descriptive nature of the investigation, as no previous works were found after the analysis of the literature. The application of questionnaires was not considered adequate because it was not sought to carry out a descriptive study that allowed the extrapolation of results to a universe from a sample using statistical techniques, nor to verify any hypothesis from the data obtained.

The research technique applied to data collection was to conduct semi-structured in-depth interviews. The researchers collected data as audio-taped interviews which were transcribed verbatim before data analysis was performed. In-depth interviews are an unstructured way to recall information that allows a deep knowledge of situations, problems or phenomena [75]. There are neither fully defined nor closed questionnaires to do an interview, only an orientation script for the interviewer that depends on the objectives of the study and the information collected in the analysis of the documentation that is considered interesting to confirm with the interviewee. Face-to-face conversations provide much richer information than other techniques, such as surveys, because they allow clarifying of doubts and obtaining a good number of details. Individuals construct their life narrative based on their experiences [76], which is an act of interpretative knowledge. A manual analysis method was used to code the data, with an interpretative approach to determine the respondents' assumptions of the world in general, and of the topic in particular. The life stories connect the past, present and potential future: through life narratives, individuals can make sense of their own lives and construct realities [77]. As a direct method of data collection, interviews allow the users to define the habits and needs or uses they make of the information requested, which gives more depth to the research results. Thus, qualitative methods allow to understand how local retailers live the opportunity of being part of an online marketplace, through the study and interpretation of their day by day narrative and business situation.

The principle of the saturation point was used to determine the size of the qualitative sample, whereby, from a certain number of units, new cases tend to repeat (saturate) the content of the previous 
knowledge. Usually, the number of cases needed to achieve the saturation point is estimated between twenty and thirty; in this investigation, sixty personal interviews to local retail managers and owners were conducted until that point was reached.

In-depth interviews were performed during the first half of 2018 with small retailers' residents in Zaragoza (Spain) with different digital profiles. In order to achieve the objectives, the interviewees were selected approaching their professional and geographical proximity with the researcher. These conditions ensured the desired communicational exchange, not structured by factors of social or cultural status, or the inhibitions that the interviewee may feel in an alienated discursive context but based on issues and objectives imposed [78].

Two variables were considered: the size of the business (number of workers and number of stores) and its presence on the Internet (according to the type of website and percentage of online sales volume):

1. According to the size, businesses were classified in two groups: small (S), with 1 or 2 workers and 1 physical store, and large (L), with more than 2 workers and more than 1 physical store.

2. Regarding their presence on the Internet, new Burgess Classification [79] was used, where the presence of a business on the Internet is classified in a pyramid depending on its web model. To this categorization was added the percentage of the volume of online sales over the total sales. All this allowed to categorize the interviewees in three groups:

- Low (L): basic web presence (static content site and/or social networks) and no online sales (0 percent of sales).

- Medium (M): medium web presence and added value websites (transactional sites and social networks) with less than 30 percent of online sales.

- High (H): online database websites and payment web presence (transactional sites, presence in marketplaces and social networks) with more than 30 percent of online sales.

The 60 interviews were distributed, based on the criteria cited, as follows: 20 interviews to retailers with low online presence, 10 to small and 10 to large businesses; 20 interviews to retailers with medium online presence, 10 to small and 10 to large businesses; and 20 interviews to retailers with high online presence, 10 to small and 10 to large businesses. The types of traditional stores that participated in the study were fashion $(\mathrm{F})$, accessories $(\mathrm{A})$, sports $(\mathrm{S})$, gifts $(\mathrm{G})$, books $(\mathrm{B})$, furniture (Fu) and décor $(\mathrm{D})$; excluding shops selling customized products or services since they always prioritize assisted sales and franchises due to a lack of strategic decisions (see Appendix B).

The codification used in Section 4 to identify the interviewees and to present the results of the interview has been: interviewee correlative number, business size, sector, web presence and initial letter of the company's name. For example, a large sport business with medium web presence called Everywheresports had been coded as 25-LSME. This codification has allowed to guarantee, for commercial reasons, the anonymity of the interviewees. Additionally, the codes facilitate the identification and categorization of the surveys and the interpretation of the results for the validation of the propositions.

The findings obtained from a previous competitive intelligence report made by the researchers about the local online marketplaces were used in the interviews, guiding the script towards the object of investigation and offering a presentation of the sector to the interviewees, due to the absence of similar studies that could serve as a reference to elaborate the questions. Following the classic definition of Bergeron and Hiller [80], competitive intelligence consists in the collection, transmission, analysis and dissemination of relevant information publicly available and ethically and legally obtained, to produce actionable knowledge for the improvement of the process of decision making. This report was conducted combining gathering and analysis techniques of environmental information. The data have been collected mainly from primary sources: e-commerce platforms and human intelligence networks (customers, experts, journalists, university professors, shareholders and suppliers); and also, from secondary sources as specialized websites and professional magazines in the matter. The 
fundamental principle of intelligence of never accepting a single information authority [81] was respected for the analysis of the information obtained. The global trends and main actors in the online marketplace sector were identified. The analysis of the main local online marketplaces that operate in Spain and their relationship with the small retail consisted on the description and analysis of the basic package that the platforms propose to their customers: partners of each platform, operations, economic conditions of entry, type of digital tools, communication and marketing support and so on. The platforms under study were: El Corte Inglés, PC componentes, Glovo, Wotika, Discubre, Mercado 47, Aplázamelo, Deanshop, Leondecompras, Manzaning, Chopit, Deliberry, Glossh, Optisoop, Promofarma, Runnics, Todocolección, and Dupon marketplace.

The guide used to conduct the interviews was focused on knowing the retailer opinion and its potential fears and opportunities towards being part of a local online marketplace and, more specifically, there were questions about the need of a digital transformation: delivery, management support, integration with accounting and order system, and initial costs and sales commissions (Appendix A). The goal of the interviews was not to discover the knowledge that retailers have about e-marketplaces in general, but to know the specific expectations and demands they have regarding a local e-marketplace, that is, one formed by shops from the same place that can operate as a complement to their physical stores. The introduction of questions related to the considerations, the interests and the assumptions of the retailers are due to the interest to identify their future expectations more than their analysis of the actual technologies. The intelligence report previously made helped to conduct the interviews in this way.

A pilot interview was first conducted in order to identify the estimated duration of the interviews as well as to make improvements in the formulation of the issues and to verify their relevance to the study. As a result of this pilot interview, the number of questions was raised to twenty, after dividing some and clarifying the content of others in order to speed up the interview process and not losing substantial elements of analysis.

An email was sent to each respondent as a previous step to the interviews, explaining the objectives of the investigation and requesting their contribution. After receiving a positive response, the date and time for the interviews in their stores were specified. Each interview lasted between 30 and $45 \mathrm{~min}$. Spontaneity in response was always looked for in interviews, trying to have a minimal effect on respondents and using a semi-open script to facilitate the production of information without a preconceived design. It was also decided to be flexible enough to allow action and feedback by the interviewer and follow the advice of Taylor and Bogdan [82] and not to play a question-answer exchange but maintain a conversational structure.

Maxwell's proposal [83] has been followed for the analysis of the responses, the validation of propositions and the credibility of conclusions in a qualitative study. Repeated interviews helped to rule out spurious associations and allowed to develop alternative arguments during the course of the research. Furthermore, two midterm contrast interviews were conducted with the intention of discovering if the interviews addressed all the substantial issues and if the saturation point was being achieved. According to Maxwell's recommendations, intensive interviews allowed to collect rich data to avoid the prejudices and expectations of the researchers, as seminal Becker's suggestions argued [84]. To streamline the data collection process and facilitate communication between the researcher and the respondents during the interviews, a digital voice recorder was used through the prior consent of the interviewees. In addition, annotations were made during the interviews. These notes were of great importance to ensure the registration of key aspects, to highlight the main ideas expressed by the interviewee and to promptly reflect nonverbal reactions [85]. Finally, to validate the first answers about the retailer's expectations, four closing questions were made at the end of each interview. 


\section{Presentation and Discussion of Results}

\subsection{Small Retail Position with Respect to Local Shopping Platforms}

In general, it can be said that the proposed idea of a local e-marketplace is interesting for the businesses interviewed, especially for those with a low level of digitalization. Speeches such as: "the future goes there" (4-SFLF), "it would boost local commerce" (31-SGLM); "a new sales channel" (18-LAML); "it will give greater visibility to small businesses" (52-LGLH), "it would allow small businesses to compete" (26-SFLC); "people who come from other neighborhoods at a specific time and so can continue to buy from me without coming here" (19-LSMA); and "it would serve to join forces" (39-LDHG) are identified.

The next main strengths were perceived: initiative linked to the region; opportunity to compete; the platform facilitates the entire process involved in selling online; possibility to offer something as interesting as what Amazon offers locally; customer acquisition and higher sales, greater product movement; possibility of connecting with more of the public and becoming known; and possibility of loyalty to customers of the physical store and increase in the sale of replacement.

On the contrary, respondents recognized the following weaknesses: need for individual advice and to adapt the conditions to each trade; difficulty to compete in price with other platforms (Amazon); and disbelief and skepticism towards the true strength of the initiative after exploring other platforms. Besides, the highly specialized shops, with a superior market to the local, doubt the profitability that the digital marketplace can bring them.

The results are similar to those found by a recent survey conducted among 223 local owneroperated retail outlets from 26 cities in Germany: a positive attitude towards digitalization, but the existence of multiple barriers such as lack of available resources and a low perception of external pressures to digitize their businesses [68]. However, it has not been identified that barriers to the implementation of e-commerce in SMES related with environmental factors such as government intervention, public administration position and external pressure from suppliers and buyers, which was identified in a study conducted with seven small businesses located in Southern Italy in the beginning of e-marketplaces [57].

\subsection{Small Retails' Valuation about Local Shopping Platforms' Services}

\subsubsection{Subscription Models}

The intelligence report about local online marketplaces allowed to identify the following alternative subscription models. The first model is the fixed fee system, with a basic package of services (software, servers and maintenance) and additional services for acquiring others, such as marketing ("Plans", "Licenses"). The second model is the collection of commissions on the merchandise sold, ranging in the analyzed companies between $5 \%$ and $25 \%$, determined largely by the product category. In the mixed subscription model, some marketplaces require a fixed fee plus commission for sale. Finally, the supplementary charge for shipping model offers the possibility of sending the goods to the customer by their own means (Deliberry, Glovo) and even a storage.

There is a preference among the interviewees for a commission's model based on a percentage of the transactions/sales value more than a flat fee subscription, given the perception that the fixed amount will be extremely high. The existence of a flat fee is related to the perception of a platform that thinks more about its own revenue than in the profitability of the sellers, the greater fear of retailers without online sales experience: "I would feel more comfortable with a commission model, because then the platform would not only focus on attracting retailers but also on getting them to sell" (49-SFLC). Hence, the commission fee that would be transferred to the platform would depend on each company and it would be different between products. The retailers with lower margins recognize that, depending on the type of product, the sale may not be profitable because the commission fee of the platform can "remove profit margin to retail" (56-LFuLA). 


\subsubsection{Online Order Management: Payment and Shipping}

All marketplaces offer a comprehensive online shopping service, including payment. However, there are occasions in which the objective of the marketplace is to attract the public to the physical establishment to incentivize its services, as well as the purchase and collection of products in their premises. In other cases, customers are offered the possibility to ask for an estimate, and professionals or companies interested will contact them to provide them with information about the services and products requested.

The payment gateways most used by marketplaces are Banco Santander Elavon, Ayden and Redsis. The usual means of payment are transfer or deposit account, credit card, gift card, Paypal, cash on delivery and cash at the physical store.

Concerning the shipping, there are three models: first, set their own shipping costs and delivery times; second, manage transport as a key aspect of their income generation (Glovo, Deliberry, etc.); and, lastly, seek alliances with companies specialized in last mile transportation and a national presence.

Delivery agreement and payment methods are not considered strategic aspects for businesses. There is no rejection when working with a different delivery service provider or financial entity if the conditions will be competitive. All businesses are open to study the possible improvements in their delivery and financial conditions. Although this is not a strategic issue, it seems to be the most attractive aspect for being part of the local online marketplace, as obtaining good conditions are decisive for becoming a competitive vendor, especially for businesses with little previous online experience. It is expressed by retailers as follows: "I really do not care which particular bank will handle the payment, but I will be glad and it could be decisive if the platform offers me better conditions than the ones I already have" (1-LFLA).

Other barriers traditionally identified in the literature to the Small and Medium-Sized Enterprises (SMEs) participation in e-marketplace such as lack of standards, supply chain integration and global trading are not referenced [24]. This could be consistent with the positive evolution of the industry in these aspects.

\subsubsection{Marketing and Communication Support}

Most marketplaces offer a private microsite or corner with general information and showcase from which they can directly promote and market their products or services. The most advanced marketplaces offer brand promotion and customer attraction services such as sponsorships (events, packaging, bloggers), keyword sponsoring, newsletters, content marketing (e.g., RSS), press coverage, specialized blogs, digital media, display campaigns and adwords investment. Almost all marketplaces have a presence on Facebook, Twitter and Instagram, with a very limited number of followers in most cases. Main loyalty practices include points programs, clubs, purchase cards, gift cards, free first buy, free shipping, deferred payments, offers and promotions, sweepstakes and contests, cross sales and invite a friend.

From the point of view of the interviewees, it is considered necessary that such platforms have an effective communication strategy through social networks and geolocation. They expressed it as follows: "If the platform wants to be success, I suppose there will be resources to encourage a powerful promotion strategy. I expect a strong communication planning that will benefit my business" (52-LGLH). However, the stores with previous online presence have marketing and social media solutions already, so they do not demand these services: "I will expect a promotion strategy in social media, but for me it is not crucial because I have my own social media actions" (12-SSMC).

The demand of digital tools and applications for administration and marketing that could work as a suitable trigger to promote digital development has not been indicated in contrast to other studies [68]. 


\subsubsection{Other Value Options}

The following options of interest are also mentioned as possible: advertising on banners or homepages for specific campaigns (Christmas, Valentine's Day, etc.); having discounts or special conditions between partners, that is, between shops attached to the platform; jointly negotiating the price of the website's security certificate with Google for each store; establishing a shared negotiation option with suppliers; or acting as a purchasing center. In this sense, retailers talked about different services: "I will expect special offers to my business from other partners, I would do it, and it will be a win-win strategy" (13-LDMD); or "For me, it will be great to have some help with all Google security certifications and other stuff like that ... I have no experience at all, and I suppose it is very difficult doing it by yourself" (3-SBHA).

\subsection{Validation of Propositions}

Analyzing local retail business managers' narratives and stories when being asked about their reality confirms Proposition 1 (online marketplaces expectations depend on the business size) and Proposition 2 (expectations depend on previous online presence). Accordingly, the investigation has let to categorizing the local business retails into six groups with different attitudes depending on their size, presence and experience in the online world, as described in Table 1.

Table 1. Local retail categorization depending on size and online presence. Source: own illustration.

\begin{tabular}{ccccc}
\hline & & \multicolumn{3}{c}{ Business Size } \\
\cline { 2 - 5 } & & \multicolumn{2}{c}{ Small } & Medium-Big \\
\hline \multirow{3}{*}{ Online Presence } & 1. & No time and no resources & 2. Novel believer \\
\cline { 2 - 5 } & Medium & 3. I am what I am & 4. Unbeliever \\
\cline { 2 - 5 } & High & 5. Pure player & 6. No gain \\
\hline
\end{tabular}

1. Small size businesses with low online presence do not have management systems and are not very computerized. They show a clear rejection towards the idea of integrating their sales into an online marketplace, despite the fact that it is local. The refusal is based, mainly, on the lack of time and human resources to undertake the management of the online sale of its articles. Usually, these businesses work with a large number of references and just one or two workers in a single physical store. Their fear lies in the lack of staff to start an online sales process that they perceive as "a process that requires a lot of dedication and I do not have enough staff to do that" (21-SALB), adding that they cannot afford to hire a person dedicated to online sales given that their volume is uncertain: "I can't hire someone just to see how the online sales experiment works out. I can't afford it" (7-SSLA). The fact of working with a large number of references in their portfolio is also a great handicap that justifies their rejection: "I cannot imagine taking pictures of everything we sell ... it would be madness" (44-SFuLH). It may surprise that small retailers with low online presence still have low interest and perceive no gain in going to this kind of e-commerce, but they explain that they have no time and resources to dedicate to a local platform. They assume the danger this attitude represents for their survival because they do not have human and financial resources to face the digital transition. This finding is in line with the conclusions of previous studies [24].

2. Medium-large businesses with low online presence have been called "novel believers" given their interest in online sales but their little or nonexistent experience in the online world. Unlike the previous ones, these businesses do not show rejection because of a lack of staff: they have stores with more than two workers and think they can handle a part-time dedication of one of their employees to manage the e-commerce. However, their biggest fears are related to the lack of experience in terms of stock control, order management and portfolio digitalization in an online context. In this sense, their expectations are focused on marketplace support, advice on the use of 
the platform, portfolio digitalization and the processes of order management and stock control. They also ask for the compatibility between the sales platform and their management systems. It is evident that medium-large businesses are interested in having online presence, but they ask local platforms for tailor-made solutions to resolve their needs.

3. Small businesses with a medium online presence, denominated in this research "I am what I am", show rejection towards this kind of sales channel based on previous unsuccessful experiences in e-commerce, either with their own online store or with online marketplaces. Their greatest fear is making an effort without receiving a reward, something accurately summed up in the following idea: "Dedicating the few resources we have, just for 1\% sales increase is not worth it. I have to worth my time. I prefer my way of doing things, it works well" (5-SFMB). Their expectations are more concrete than those of the previous groups, and they are focused on the value that the online platform offers: flexible services contracts to take advantage of their own structure, no high investment, real sales and profitability increase, delivery performed by the platform and support to register new articles, and adding references available from suppliers.

4. Medium-large businesses with medium online presence work actively through e-commerce, so they have experience in their management. Their online sales do not represent more than $30 \%$ of their total turnover. Online orders are managed relying on shopping carts, social media or email. They have been named "unbelievers" because of their great disbelief regarding the proper functioning of a local online marketplace, given the existence of strong players like Amazon or Alibaba in online retail. However, in the case that the local online marketplace may compete with other platforms, "unbelievers" find certain opportunities related to profitability and sales growth as long as the technology used by the platforms is compatible with theirs. Thus, they expect local online platforms to provide the following: sales growth and increased profitability, trial period to check the worth of the investment, flexibility to choose the services of the platform, and central purchasing advantages.

5. The group number 5 "pure players" refers to business with a maximum of two employers that have opted exclusively for the online store as their business model. Given its exclusive online retail character, "pure players" are outside of this study. None of the small merchants interviewed belong to this group.

6. Finally, medium-large retailers with high online presence, called "no gain", do not perceive any benefit from being part of a local marketplace since, despite their status as local retail, more than $30 \%$ of their sales are online and their market is both domestic and international. The high percentage of online sales is managed through third-party platforms and there is a high dedication of both economic and personal resources to their own e-commerce. Due to their high online experience and multichannel trade character, they do not consider it attractive to be part of a local online marketplace: "I do not see the benefit. I already sell online, and I sell outside the local market. The one who lives here comes to my shop and the one who lives in another region buys in my "e-comm" ... I am very well positioned" (14-LBHL). They only find it interesting to be part of the local platform if it has many active users as well as influential and well-known brand local stores as vendors. To these businesses, a local online marketplace is basically another way of advertising at the local market rather than a sales channel. Their expectations are basically the same as they have towards platforms like Amazon: flexible membership vendor formula, central purchasing advantages, total efficiency (zero failures, and, if any, the platform assumes them) and compatibility with other platforms, management and order systems.

\section{Conclusions}

The methodological process followed in this investigation has proved valid to identify the perception and expectations that local small stores have on local online sales platforms and to validate the two initial propositions. The interviews allowed us to verify that the factors that determine the incorporation of a local retailer in a local marketplace are the size of the company and its previous online 
presence: the small stores characterized by a low digitization and the large ones with a high previous online presence showed no interest in this service; however, the stores that were in-between showed a high interest. No changes were detected during the interview about the interest to be part of a local online sales platform, as confirms the similar responses to initial and closing questions, despite having discussed the expected advantages, operation and opportunities of the digital transformation process. There were also no significant variations related to the store's business sector.

Therefore, there are different types of retailers regarding their attitude towards being part of a local online marketplace as vendors. There is a gap between the traditional small non-digitized business, the "no time, no resources" retailers, and those businesses that can afford an e-commerce model- "novel believers" and "I am what I am" retailers-or those whose model is based on the Internet- "unbelievers" and "no gain" retailers. The former encounters different types of resistance by feeling unable to face e-commerce inversions. The latter, except "unbelievers" and "no gain" retailers, are very interested in the creation of a local online marketplace as they perceive so many opportunities and their fears disappear if the platform offers a good technical and marketing support to the sellers. In this sense, they are aware of the development of e-commerce and the strength of a multichannel strategy to increase sales, which makes them very interested in being part of a local project of this type, especially if they obtain advantages in purchasing conditions, good logistics agreements or preferential financing of payments. Finally, "unbelievers" and "no gain" businesses do not find any strategic interest, as they consider themselves competitive enough inside the online world. In spite of this, they give a vote of confidence to the creation of a local online marketplace and seem to be interested in becoming part of it, but especially if the following conditions occur: the promoters are living forces of the city, represented by leading delivery, finance, mass media and technological companies, which ensure the proper functioning of the platform, with zero failures and a valuable offer able to compete with the giants.

The main contribution of this research to the literature in electronic commerce is its focus on the future perceptions and expectations of the local retailers about local e-marketplaces, in an area where studies on customer expectations prevail, as it was revealed in the previous state of art. The smart-sustainable city literature needs works that explore new business models, especially in commerce, due to its impact on the economy and the quality of life of the cities. The results show the interviewed retailers, despite certain reservations expressed by a group, have a positive attitude to the local online marketplaces. The belief in the possibilities that offer these platforms is in line with the theoretical construction of the concept of smart-sustainable cities based on the use and control of technologies by local agents.

The propositions mentioned above offer different future researches in order to confirm the relevance of the explanations and the robustness of the identified patterns. Our qualitative research has generated propositions that could be refined into hypotheses by quantitative empirical testing. Additionally, future research should focus on conducting a complete analysis of the consumer and knowing their opinion about an online market with local companies, detailing their perceptions, attitudes and motives, placing a special emphasis on a possible cut in delivery times and the fact that wealth is generated in the area where the clients have their habitat; identifying the minimum size a population must have for its implementation; defining the means and messages that will be used for an effective communication, able to eliminate resistance from small non-digitized companies; measuring the advertising impact in terms of cost savings for small businesses; and studying margins by sectors, groups or families of products in order to establish priorities for the incorporation of stores to the marketplace. Furthermore, conducting the same researches in other locations would help to ensure the results.

Finally, during the interviews we observed that, as described in the theorical background, the offer of a local online marketplace can mean a real change in the status quo in terms of the commercialization models of small local retail in big cities. Despite the perceptual and attitudinal differences, and regardless of the type of products sold, all interviewed merchants have assumed that 
the current and future business models go through the digitalization of their businesses and the selling through e-commerce platforms. The coexistence of e-marketplace and physical stores conducted by the same retailers could be a strategy to maintain the commercial activity in the cities, which could have a positive effect in two dimensions that concern urban sustainability; specifically, in the economic strengthening and renovation of the historical centers and in the maintenance of the population and traditional social relationships, avoiding processes of degradation and gentrification.

Author Contributions: Conceptualization, T.B.-L.M. and M.-Á.G.-M.; data curation, M.-Á.G.-M. and M.-Á.E.-N.; formal analysis, M.-Á.G.-M. and M.-Á.E.-N.; investigation, J.-F.D.-d.M. and T.B.-L.M.; methodology, T.B.-L.M., M.-Á.G.-M., J.-F.D.-d.M. and M.-Á.E.-N.; project administration, T.B.-L.M.; supervision, J.-F.D.-d.M.; validation, M.-Á.E.-N.; visualization, M.-Á.G.-M.; writing—original draft, J.-F.D.-d.M. and M.-Á.G.-M.; writing一review \& editing, J.-F.D.-d.M. and M.-Á.E.-N. All authors have approved the submitted version, have agreed to be personally accountable for their own contributions and have ensured that questions related to the accuracy or integrity of any part of the work, even ones in which the author was not personally involved, have been appropriately investigated, resolved and documented in the literature.

Funding: This research received no external funding.

Conflicts of Interest: The authors declare no conflict of interest.

\section{Appendix A. Semi-Structured Script for in-Depth Interviews}

Introduction. Hello. First of all, thank you very much for your collaboration. We are doing a study about the participation of local retailers into a local online sales platform and we would like to know your opinion.

1. Could you explain by your own words what an e-marketplace is, please?

2. Do you consider a local online sales platform interesting for your business?

3. Could you explain the reasons why?

Retailers' expectations. Imagine that you decide to be a part of a local platform:

4. What would you demand from this local platform?

5. How would you presume the selling process for your business?

6. Would you like to get support from the platform in your business?

7. How would you like the platform to manage the digital transformation process of your business?

Digital transformation services. Now, we are going to talk about the digital transformation that some businesses need to be part of a local online platform.

8. Would you need an initial evaluation of your digital system? Why?

9. Have you got any fears towards starting to sell online? Why? If so, could you explain your fears, please?

10. Would you need any technical digital support to start to sell in the platform? What kind of support would you like? Note: If they do not know, suggest portfolio photographs, portfolio loading, initial stock management, etc.

Advantages expected - credibility level. The advantage of these local platforms is that they have more resources than a small business and get better search engine rankings.

11. Would you find interesting this advantage? Why?

12. What kind of marketing support would you like the platform to offer you?

13. How would you expect the purchasing and order processes?

14. Would you have any fear about the compatibilization with your current system?

15. What would you expect about the payment process?

16. Would you like to add any service to this local sales platform? 
Closing questions.

17. Would you consider including your business in a local platform? Why? Note: If the rejection is due to the fact that the store has its own sales website, explain that the online platform will not compete with its website but rather extends the reception of orders by having a better positioning in search engines such as Google.

18. If so, would you prefer a \% commission or a fix fee subscription model? Why? Would you explain your opinion in detail please?

19. Would you prefer your own delivery service, or a delivery service provided by the platform? Why? Explain in detail please.

20. Do you want to add something else?

Thank you very much for your comments and ideas. 


\section{Appendix B. Companies Interviewed}

\begin{tabular}{|c|c|c|c|c|c|}
\hline $\begin{array}{c}\text { Interviewee } \\
\text { Correlative Number }\end{array}$ & Business Size & Sector & Web Presence & $\begin{array}{l}\text { Initial Letter of the } \\
\text { Company's Name }\end{array}$ & CODE \\
\hline 1 & LARGE & FASHION & LOW & A & 1LFLA \\
\hline 2 & SMALL & ACCESSORIES & LOW & $\mathrm{B}$ & 2SALB \\
\hline 3 & SMALL & BOOKS & HIGH & $\mathrm{A}$ & 3SBHA \\
\hline 4 & SMALL & FASHION & LOW & $\mathrm{F}$ & 4SFLF \\
\hline 5 & SMALL & FASHION & MEDIUM & B & 5SFBM \\
\hline 6 & LARGE & ACCESSORIES & LOW & A & 6LALA \\
\hline 7 & SMALL & SPORTS & LOW & A & 7SSLA \\
\hline 8 & LARGE & ACCESSORIES & LOW & $\mathrm{H}$ & 8LALH \\
\hline 9 & LARGE & SPORTS & LOW & $\mathrm{D}$ & 9LSLD \\
\hline 10 & LARGE & SPORTS & MEDIUM & A & 10LSMA \\
\hline 11 & LARGE & GIFTS & MEDIUM & $\mathrm{L}$ & 11LGML \\
\hline 12 & SMALL & SPORTS & MEDIUM & $\mathrm{C}$ & 12SSMC \\
\hline 13 & LARGE & DÉCOR & MEDIUM & $\mathrm{D}$ & 13LDMD \\
\hline 14 & LARGE & BOOKS & HIGH & $\mathrm{L}$ & 14LBHL \\
\hline 15 & SMALL & GIFTS & LOW & M & 15SGLM \\
\hline 16 & LARGE & FURNITURE & MEDIUM & $\mathrm{B}$ & 16LFuMB \\
\hline 17 & LARGE & DECOR & MEDIUM & $\mathrm{C}$ & 17LDMC \\
\hline 18 & LARGE & ACCESSORIES & MEDIUM & $\mathrm{L}$ & 18LAML \\
\hline 19 & LARGE & SPORTS & MEDIUM & A & 19LSMA \\
\hline 20 & SMALL & GIFTS & LOW & $\mathrm{L}$ & 20SGLL \\
\hline 21 & SMALL & ACCESSORIES & LOW & B & 21SALB \\
\hline 22 & LARGE & FASHION & LOW & B & 22LFLB \\
\hline 23 & LARGE & DECOR & LOW & $\mathrm{L}$ & 23LDLL \\
\hline 24 & LARGE & DECOR & MEDIUM & $\mathrm{J}$ & 24LDMJ \\
\hline 25 & LARGE & FURNITURE & MEDIUM & $\mathrm{N}$ & 25LFuMN \\
\hline 26 & SMALL & FASHION & LOW & $\mathrm{C}$ & 26SFLC \\
\hline 27 & SMALL & FASHION & MEDIUM & $\mathrm{C}$ & 27SFMC \\
\hline 28 & SMALL & GIFTS & MEDIUM & $\mathrm{J}$ & 28SGMJ \\
\hline 29 & SMALL & BOOKS & HIGH & $\mathrm{L}$ & 29SBHL \\
\hline 30 & SMALL & FURNITURE & MEDIUM & $\mathrm{B}$ & 30SFuMB \\
\hline 31 & SMALL & GIFTS & LOW & M & 31SGLM \\
\hline 32 & LARGE & DECOR & LOW & $\mathrm{O}$ & 32LDLO \\
\hline 33 & LARGE & DECOR & LOW & $\mathrm{P}$ & 33LDLP \\
\hline 34 & SMALL & DECOR & MEDIUM & $\mathrm{T}$ & $34 \mathrm{SDMT}$ \\
\hline 35 & SMALL & GIFTS & HIGH & $\mathrm{T}$ & 35SGHT \\
\hline 36 & LARGE & SPORTS & HIGH & $\mathrm{F}$ & 36LSHF \\
\hline 37 & SMALL & BOOKS & HIGH & $\mathrm{L}$ & 37SBHL \\
\hline 38 & LARGE & FASHION & HIGH & B & 38LFHB \\
\hline 39 & LARGE & DECOR & HIGH & G & 39LDHG \\
\hline 40 & SMALL & GIFTS & HIGH & G & 40SGHG \\
\hline 41 & SMALL & FURNITURE & HIGH & $\mathrm{F}$ & 41SFuHF \\
\hline 42 & SMALL & DECOR & MEDIUM & G & 42SDMG \\
\hline 43 & SMALL & BOOKS & MEDIUM & $\mathrm{Z}$ & 43SBMZ \\
\hline 44 & SMALL & FURNITURE & LOW & $\mathrm{H}$ & 44SFuLH \\
\hline 45 & LARGE & DECOR & MEDIUM & $\mathrm{N}$ & 45LDMN \\
\hline 46 & LARGE & FURNITURE & HIGH & $\mathrm{F}$ & 4LFuHF \\
\hline 47 & LARGE & GIFTS & HIGH & $\mathrm{E}$ & 47LGHE \\
\hline 48 & LARGE & GIFTS & HIGH & $\mathrm{F}$ & 48LGHF \\
\hline 49 & SMALL & FASHION & LOW & $\mathrm{C}$ & 49SFLC \\
\hline 50 & SMALL & BOOKS & MEDIUM & $\mathrm{L}$ & 50SBML \\
\hline 51 & SMALL & BOOKS & HIGH & $\mathrm{L}$ & 51SBHL \\
\hline 52 & LARGE & GIFTS & LOW & $\mathrm{H}$ & 52LGLH \\
\hline 53 & SMALL & GIFTS & HIGH & G & 53SGHG \\
\hline 54 & LARGE & BOOKS & HIGH & $\mathrm{L}$ & 54LBHL \\
\hline 55 & LARGE & ACCESSORIES & HIGH & $\mathrm{C}$ & 55LAHC \\
\hline 56 & LARGE & FURNITURE & LOW & A & 56LFULA \\
\hline 57 & LARGE & SPORTS & HIGH & $\mathrm{F}$ & 57LSHF \\
\hline 58 & SMALL & ACCESSORIES & HIGH & B & 58SAHB \\
\hline 59 & SMALL & FASHION & HIGH & $\mathrm{P}$ & 59SFHP \\
\hline 60 & SMALL & FASHION & MEDIUM & $S$ & 60SFMS \\
\hline
\end{tabular}

Note: This codification guarantees, for commercial reasons, the anonymity of the interviewees. 


\section{References}

1. Erosa, V.E. Innovación para la Competitividad: Distintos significados en el Comercio Minorista. In Proceedings of the $4^{\circ}$ Congreso Internacional de Sistemas de Innovación para la Competitividad SINNCO, Consejo de Ciencia y Tecnología del estado de Guanajuato, Universidad Iberoamericana, León, Mexico, 26-28 August 2009.

2. Cadeaux, J.; Dubelaar, C. Market environment, assortment policy, and performance of small retailers. Australas. Mark. J. 2012, 20, 250-259. [CrossRef]

3. De Kok, J.; de Wit, G. Do Small Businesses Create More Jobs? New Evidence for Europe. Small Bus. Econ. 2014, 42, 283-295. [CrossRef]

4. Berman, B.; Evans, J.R. Retail Management: A Strategic Approach, 10th ed.; Pearson Education: Upper Saddle River, NJ, USA, 2007.

5. Dixon, T.J. The Role of Retailing in Urban Regeneration. Local Econ. 2005, 20, 168-182. [CrossRef]

6. Warnaby, G.; Benninson, D.; Davies, B.J. Marketing communications in planned shopping centers: Evidence from the UK. Int. J. Retail Distrib. Manag. 2005, 33, 893-904. [CrossRef]

7. Simó, M.; Canelles, A.; Avellaneda, P. Comercio minorista y peatonalización: Evolución y adaptación en la ciudad costera de Malgrat de Mar (Barcelona). An. Geogr. Univ. Complut. 2018, 38, 219-238. [CrossRef]

8. Gómez, P. El comercio de barrio como espacio de sociabilidad en contextos locales de migración. PolisRev. Latinoam. 2013, 12, 143-163. [CrossRef]

9. Feinleib, D. Bricks to Clicks: Why Some Brands Will Thrive in E-Commerce and Others Won't; Springer Science + Business Media: New York, NY, USA, 2017.

10. Wrigley, N.; Lambiri, D. High Street Performance and Evolution: A Brief Guide to the Evidence; University of Southampton: Southampton, UK, 2014; Available online: http://hegreatbritishhighstreet.co.uk/pdf/GBHSHighStreetReport.pdf (accessed on 5 September 2018).

11. Standing, S.; Standing, C.; Love, P.E.D. A review of research on e-marketplaces 1997-2008. Decis. Support Syst. 2010, 49, 41-51. [CrossRef]

12. Ahlers, R.; Lackes, R.; Ruegenberg, A.; Samanpour, A.R.; Sipermann, M.; Weber, P. Are Local Retailers Conquering the Long Tail? A Web Usage and Association Rule Mining Approach on Local Shopping Platforms. In Proceedings of the 2018 Multikonferenz Wirtschaftsinformatik, Lüneburg, Germany, 6-9 March 2018.

13. PWC. Rethinking Retail: The Role of the Physical Store. 2018. Available online: https://www.pwc.be/en/ documents/20180627-rethinking-retail.pdf (accessed on 20 July 2019).

14. Coleman, P. Shopping Environments: Evolution, Planning and Design; Routledge: Abingdon, UK, 2006.

15. McNair, C. Worldwide Retail and Ecommerce Sales: eMarketer's Estimates for 2016-2021; eMarketer: New York, NY, USA, 2017.

16. Verhoef, P.C.; Kannan, P.K.; Inman, J.J. From Multi-Channel Retailing to Omni-Channel Retailing. J. Retail. 2015, 91, 174-181. [CrossRef]

17. Knezevic, B.; Pejic-Bach, M.; Strugar, I. Top European Retailers and Customer-Centered Web Structuring. Zagreb Int. Rev. Bus. Econ. 2007, 10, 67-83.

18. NCSC (Nordic Council of Shopping Centers). Online Retail-Threat or Opportunity for Shopping Centers. Annual Research-Report No. 1. October 2013. Available online: http://ncscnordic.org/wp-content/uploads/ 2014/07/NCSC-report-2013_Online-Retail_lowENG.pdf (accessed on 20 July 2019).

19. McKinsey. 2019. Perspectives on Retail and Consumer Goods, n. 7, January 2019. Available online: https://www.mckinsey.com/ \{\}/media/McKinsey/Industries/Retail/Our\%20Insights/Perspectives\%20on\% 20retail\%20and\%20consumer\%20goods\%20Number\%207/Perspectives-on-Retail-and-Consumer-Goods_ Issue-7.ashx (accessed on 20 July 2019).

20. Dutta, D.K. In Competition with Oneself: A Qualitative Inquiry into Amazon's Entrepreneurial Culture. Technol. Innov. Manag. Rev. 2018, 8, 5-14. [CrossRef]

21. Duch-Brown, N. The Competitive Landscape of Online Platforms, JRC Digital Economy Working Paper 2017-04; European Commission: Seville, Spain, 2017.

22. Goode, S. Management attitudes toward the World Wide Web in Australian small business. Inf. Syst. Manag. 2002, 19, 45-48. [CrossRef]

23. Korchak, R.; Rodman, R. E-business adoption among US small manufacturers and the role of manufacturing extension. Econ. Dev. Rev. 2001, 17, 20-25. 
24. Stockdale, R.; Standing, C. Benefits and barriers of electronic marketplace participation: An SME perspective. J. Enterp. Inf. Manag. 2004, 17, 301-311. [CrossRef]

25. McKinsey. 2014. Perspectives on Retail and Consumer Goods, n. 3, Summer 2014. Available online: https://www.mckinsey.com/industries/retail/our-insights/making-stores-matter-in-a-multichannel-world? cid=other-eml-alt-mip-mck-oth-1808\&hlkid=e506164ec2dd486791719a7d4b8e7fd5\&hctky=2736659\& hdpid=e257e96e-8ca5-401d-b75a-d4616e647b73 (accessed on 20 July 2019).

26. Deloitte. 2018. Global Powers of Retailing 2018. Transformative Change, Reinvigorated Commerce. Available online: https://www2.deloitte.com/content/dam/Deloitte/global/Documents/consumer-industrial-products/ cip-2018-global-powers-retailing.pdf (accessed on 20 July 2019).

27. Robles, J. Mercados municipales y tecnologías digitales: Entre el e-comercio y nuevas formas de convivialidad. Anthropol. Del Dep. De Cienc. Soc. 2014, 32, 137-161. Available online: http://revistas.pucp.edu.pe/index.php/ anthropologica/article/view/11329 (accessed on 02 July 2019).

28. Mella, J.M.; López, A. Ciudades sostenibles: Análisis y posibles estrategias. Encuentros Multidiscip. 2015, 17, 59-68.

29. Arundel, R.; Ronald, R. The role of urban form in sustainability of community: The case of Amsterdam. Environ. Plan. B Urban Anal. City Sci. 2015, 44, 33-53. [CrossRef]

30. Polese, M.; Stren, R. The Social Sustainability of Cities: Diversity and the Management of Change; University of Toronto Press: Toronto, ON, Canada, 2000.

31. Yiftachel, O.; Hedgecock, D. Urban social sustainability: The planning of an Australian city. Cities 1993, 10, 139-157. [CrossRef]

32. Visvizi, A.; Lytras, M.D. Smart cities research and debate: What is in there? In Smart Cities: Issues and Challenges: Mapping Political, Social and Economic Risks and Threats; Visvizi, A., Lytras, M.D., Eds.; Elsevier: Amsterdam, The Netherlands, 2019; pp. 1-12.

33. European Commission. Smart Cities and Communities-European Innovation Communication from the Commission; European Commission: Brussels, Belgium, 2012.

34. Martin, C.; Evans, J.; Karnoven, A.; Paskaleva, K.; Dujuan, Y.; Linjordet, T. Smart-sustainability: A new urban fix? Sustain. Cities Soc. 2019, 45, 640-648. [CrossRef]

35. Visvizi, A.; Mazzucelli, C.G.; Lytras, M. Irregular migratory flows: Towards an ICTs'enabled integrated framework for resilient urban systems. J. Sci. Technol. Policy Manag. 2017, 8, 227-242. [CrossRef]

36. Lytras, M.D.; Visvizi, A.; Sarirete, A. Clustering Smart City services: Perceptions, Expectations, Responses. Sustainability 2019, 11, 1669. [CrossRef]

37. Rao, F. Resilient Forms of Shopping Centers Amid the Rise of Online Retailing: Towards the Urban Experience. Sustainability 2019, 11, 3999. [CrossRef]

38. Porter, M. The competitive advantage of the inner city. Harv. Bus. Rev. 1995, 73, 55-71. Available online: https://hbr.org/1995/05/the-competitive-advantage-of-the-inner-city (accessed on 11 June 2019).

39. Partridge, M.D.; Rickman, D.S.; Ali, K.; Olfert, M.R. Employment growth in the American urban hierarchy: Long live distance. BE J. Macroecon. 2008, 8, 1-10. [CrossRef]

40. Boddy, M.; Parkinson, M. City Matters: Competitiveness, Cohesion and Urban Governance; Polity Press: Bristol, UK, 2004.

41. Berdegué, J.A.; Carriazo, F.; Jara, B.; Modrego, F.; Soloaga, I. Cities, Territories, and Inclusive Growth: Unraveling Urban-Rural Linkages in Chile, Colombia, and Mexico. World Dev. 2015, 73, 56-71. [CrossRef]

42. Lowe, M. The Regional Shopping Centre in the Inner City: A Study of Retail-led Urban Regeneration. Urban Stud. 2005, 42, 449-470. [CrossRef]

43. Claxton, R.; Siora, G. Retail-led Regeneration: Why it Matters to Our Communities; DTZ: London, UK, 2008.

44. Wilson, J. The triple bottom line. Int. J. Retail Distrib. Manag. 2015, 43, 432-447. [CrossRef]

45. Chaudhary, S. Effect of E-Commerce on Organization Sustainability. IOSR J. Bus. Manag. (IOSR-JBM) 2017, 19, 15-24. [CrossRef]

46. Visser, J.; Nemoto, T.; Browne, M. Home Delivery and the Impacts on Urban Freight Transport: A Review. Procedia-Soc. Behav. Sci. 2014, 125, 15-27. [CrossRef]

47. Oláh, J.; Kitukutha, N.; Haddad, H.; Pakurár, M.; Máté, D.; Popp, J. Achieving Sustainable E-Commerce in Environmental, Social and Economic Dimensions by Taking Possible Trade-Offs. Sustainability 2019, 11, 89. [CrossRef] 
48. Fourcroy, C. Innovation logics and energy consumption in the service sector: A characteristics-based approach and its application to food retail services. Econ. Policy Energy Environ. 2014, 3, 115-138. [CrossRef]

49. Yan, Y.; Wang, C.; Quan, Y.; Wu, G.; Zhao, J. Urban sustainable development efficiency towards the balance between nature and human well-being: Connotation, measurement, and assessment. J. Clean. Prod. 2018, 178, 67-75. [CrossRef]

50. Schöder, D.; Ding, F.; Kucht, J. The Impact of E-Commerce Development on Urban Logistics Sustainability. Open J. Soc. Sci. 2016, 4, 1-6. [CrossRef]

51. Nieto-Mengotti, M.; López-Arranz, A.; Novo-Corti, I. Smart city as a platform economy: Civic engagement and self-employment in focus. In Smart Cities: Issues and Challenges: Mapping Political, Social and Economic Risks and Threats; Visvizi, A., Lytras, M.D., Eds.; Elsevier: Amsterdam, The Netherlands, 2019; pp. 63-75.

52. Nosratabadi, S.; Mosavi, A.; Shamshirband, S.; Zavadskas, E.K.; Rakotonirainy, A.; Chau, K.W. Sustainable Business Models: A Review. Sustainability 2019, 11, 1663. [CrossRef]

53. Harvey, D. The Condition of Postmodernity: An Enquiry into the Origins of Cultural Change; Blackwell Publishers: Hoboken, NJ, USA, 1991.

54. Sennet, R. Building and Dwelling. Ethics for the City; Ferrat, Straus and Giroux: New York, NY, USA, 2018.

55. Grandon, E.E.; Pearson, J.M. Electronic commerce adoption: An empirical study of small and medium US businesses. Inf. Manag. 2004, 42, 197-216. [CrossRef]

56. Daniel, E.; Wilson, H.; Myers, A. Adoption of E-Commerce by SMEs in the UK: Towards a Stage Model. Int. Small Bus. J. 2002, 20, 253-270. [CrossRef]

57. Scupola, A. The adoption of internet commerce by SMES in the south of Italy: An environmental, technological and organizational perspective. J. Glob. Inf. Technol. Manag. 2003, 6, 52-71. [CrossRef]

58. Globackhloo, M.; Arias-Aranda, D.; Benítez-Amado, J. Adoption of e-commerce applications in SMEs. Ind. Manag. Data Syst. 2011, 111, 1238-1269. [CrossRef]

59. Hänninen, M.; Smedlund, A.; Mitronen, L. Digitalization in retailing: Multi-sided platforms as drivers of industry transformation. Balt. J. Manag. 2018, 13, 152-168. [CrossRef]

60. Cliquet, G. La innovación en la distribución: El caso de Francia. Distrib. Consumo 2011, 21, $26-33$.

61. Wang, L.; Fan, H.; Wang, Y. Sustainability Analysis and Market Demand Estimation in the Retail Industry through a Convolutional Neural Network. Sustainability 2018, 10, 1762. [CrossRef]

62. Luca, M. Designing online marketplaces: Trust and reputation mechanisms. Innov. Policy Econ. 2017, 17, 77-93. [CrossRef]

63. Müller-Seitz, G.; Dautzenberg, K.; Creusen, U.; Stromereder, C. Customer acceptance of RFID technology: Evidence from the German electronic retail sector. J. Retail. Consum. Serv. 2009, 16, 31-39. [CrossRef]

64. Kurnia, S.; Choudrie, J.; Mhbubur, R.; Alzougool, B. E-commerce technology adoption: A Malaysian grocery SME retail sector study. J. Bus. Res. 2015, 68, 1906-1918. [CrossRef]

65. Galbraith, B.; McAdam, R.; Woods, J.; McGowan, T. Putting policy into practice: An exploratory study of SME innovation support in a peripheral UK region. Entrep. Reg. Dev. 2017, 29, 668-691. [CrossRef]

66. Ritala, P.; Golnam, A.; Wegmann, A. Coopetition-based business models: The case of Amazon.com. Ind. Mark. Manag. 2014, 43, 236-249. [CrossRef]

67. Navickas, V.; Krajňáková, E.; Navikaite, A. Paradigm shift of small and medium sized enterprises competitive advantage. Eng. Econ. 2015, 26, 327-332. [CrossRef]

68. Bollweg, L.; Lackes, R.; Sipermann, M.; Weber, P. Drivers and barriers of the digitalization of local owner operated retail outlets. J. Small Bus. Entrep. 2019, 31, 1-29. [CrossRef]

69. Ruiz-Real, J.L.; Uribe-Toril, J.; Gázquez-Abad, J.C.; de Pablo-Valenciano, J. Sustainability and Retail: Analysis of Global Research. Sustainability 2019, 11, 14. [CrossRef]

70. Wiese, A.; Kellner, J.; Lietke, B.; Toporowski, W.; Zielke, S. Sustainability in retailing-A summative content analysis. Int. J. Retail Distrib. Manag. 2012, 40, 318-335. [CrossRef]

71. Singleton, A.D.; Dolega, L.; Riddlesden, D.; Longley, P.A. Measuring the spatial vulnerability of retail centres to online consumption through a framework of e-resilience. Geoforum 2016, 69, 5-18. [CrossRef]

72. Lackes, R.; Siepermann, M.; Weber, P. Mind the Gap! Are Local Retailers Misinterpreting Customer Expectations Regarding Digital Services? IADIS Int. J. 2015, 13, 17-29.

73. Lackes, R.; Siepermann, M.; Sutaj, A.; Weber, P. Digitalization of Local Owner Operated Retail Outlets: The Role of the Perception of Competition and Customer Expectations. In Proceedings of the Asia Conference on Information Systems (PACIS), Chiayi, Taiwan, 27 June-1 July 2016; p. 348. 
74. Kane, G.; Palmer, D.; Phillips, A.; Kiron, D. Is Your Business Ready for a Digital Future? MIT Sloan Manag. Rev. 2015, 56, 37-44.

75. Grande-Esteban, I.; Abascal-Fernández, E. Fundamentos y Técnicas de Investigación Comercial; ESIC Editorial: Madrid, Spain, 2007.

76. Singer, J.A. Narrative identity and meaning making across the adult lifespan: An introduction. J. Personal. 2004, 72, 437-459. [CrossRef] [PubMed]

77. Shankar, A.; Elliott, R.; Goulding, C. Understanding Consumption: Contributions from a Narrative Perspective. J. Mark. Manag. 2001, 17, 429-453. [CrossRef]

78. Serbia, J.M. Diseño, muestreo y análisis en la investigación cualitativa. Hologramática 2007, 3, $123-146$.

79. Burgess, S. Representing small business web presence content: The web presence pyramid model. Eur. J. Inf. Syst. 2016, 25, 110-130. [CrossRef]

80. Bergeron, P.; Hiller, C. Competitive Intelligence. Annu. Rev. Inf. Sci. Technol. 2002, 36, 353-390. [CrossRef]

81. Berkowitz, B.D.; Goodman, A.E. Best Truth: Intelligence in the Information Age; Yale University Press: New Haven, CT, USA, 2000.

82. Taylor, S.J.; Bogdan, R. Introduction to Qualitative Research Methods: The Search for Meanings; John Wiley and Sons Inc.: New York, NY, USA, 1984.

83. Maxwell, J.A. Designing a qualitative study. In Handbook of Applied Social Research Methods; Bickman, L., Rog, D.J., Eds.; Sage Publications, Inc.: Thousand Oaks, CA, US, 1998; pp. 69-100.

84. Becker, H.S. Sociology Work: Method and Substance; Transaction: New Brunswick, NJ, USA, 1970.

85. Van Maanen, J. Qualitative Studies of Organizations (The Administrative Science Quarterly Series in Organizational Theory and Behavior); SAGE Publishing, Inc.: Thousand Oaks, CA, USA, 1998.

(C) 2019 by the authors. Licensee MDPI, Basel, Switzerland. This article is an open access article distributed under the terms and conditions of the Creative Commons Attribution (CC BY) license (http://creativecommons.org/licenses/by/4.0/). 